\title{
Aspectos da recepção alemã do Les beaux arts réduits à un même principe (1746) de Charles Batteux
}

\author{
Mônica Lucas* \\ Universidade de São Paulo (USP)
}

\section{Resumo:}

$\mathrm{O}$ artigo discute idéias contidas na obra Les beaux arts réduits à un même principe (Paris, 1746), de Charles Batteux, a partir da tradução alemã comentada por Johann Adolf Schlegel (1770). No decorrer do texto, são discutidos os conceitos de Belas Artes, de imitação musical, a idéia de natureza e o papel da razão e das paixões na obra de Batteux (e nos comentários de Schlegel), estabelecendo relações entre idéias do autor francês, fontes clássicas e o pensamento musical luterano. A seguir, são resgatados alguns aspectos sistemáticos do discurso musical mencionados por Batteux. Com isso, torna-se possível avaliar melhor a recepção da idéia de imitação musical e da música como discurso retórico na Alemanha na segunda metade do século XVIII.

Palavras-chave: poética; retórica; Batteux, música setecentista; belas artes

\footnotetext{
*Mônica Lucas graduou-se em clarinete pela Universidade de São Paulo e especializou-se na interpretação de música antiga no Conservatório Real de Haia (Holanda), obtendo diplomas em flauta-doce e em clarinetes históricos. Atua regularmente como clarinetista, concentrando-se no repertório setecentista. Dedica-se tmbém ao estudo da poética e da retórica na música do século XVIII, com pesquisas de doutorado e pós-doutorado financiadas pela FAPESP. É responsável pela disciplina "História da Música" no Departamento de Música da ECA-USP, coordenando também o Conjunto de Música Antiga desta instituição.
} 
Dentre as obras que sustentam o princípio aristotélico da imitação nas artes, Les beaux arts réduits à un même principe ["As belas artes reduzidas a um mesmo princípio"] (Paris, 1746), de Charles Batteux, foi aquela que teve maior circulação no mundo luterano na segunda metade do século XVIII. O Beaux arts foi traduzido e editado pelo menos dez vezes em alemão: por Johann Adolf Schlegel, como Einschränkung der Schönen Künste auf einen einzigen Grundsatz ["Redução das belas artes a um único princípio"] (Leipzig, 1752, 1759 e 1770); por Philipp Ernst Bertram, como Die schönen Künste aus einem Grunde hergeleitet ["As belas-artes derivadas de um só princípio"] (Gotha, 1751); por Christoph Gottsched, como Auszug aus dem Herrn Batteux ... schönen Künste ["Resumo das belas-artes ... do senhor Batteux] (Leipzig, 1754), por Karl Wilhelm Ramler, como Einleitung in die schönen Wissenschaften ["Introdução às belas ciências"] (Leipzig, 1756, 1770, 1781, 1786 e 1802). Nestas edições, os tradutores acrescentam diversos comentários à obra de Batteux, procurando acomodar as idéias deste autor à visão musical luterana. Além dessas traduções, surgiram também críticas sobre a obra em revistas musicais, dentre os quais se destaca o Sendschreiben eines Freundes an einen anderen über einige Ausdrücke des 48 Herren Batteux von der Musik ["Carta de um amigo a outro a respeito de algumas expressões do Senhor Batteux sobre a música"], de Caspar Ruetz (1754).

Este artigo examina idéias contidas no Beaux arts a partir da tradução comentada de Johann Adolf Schlegel, editada em1770, no sentido de contribuir para uma melhor compreensão dos conceitos de imitação musical e de música como discurso retórico na Alemanha na segunda metade do século XVIII.

A imitação como princípio unificador das artes na obra de Batteux é claramente fundamentada na poética clássica. No prefácio, o próprio autor afirma que a finalidade principal do tratado é comprovar a validade da Poética aristotélica. $O$ autor do Beaux arts se queixa de que, a despeito de inúmeras menções, a obra do estagirita seja desconhecida por seus contemporâneos setecentistas. Batteux diz que o ensejo para a publicação do Beaux arts é o fato de as idéias derivadas da Poética ainda não haverem sido organizadas em um 
,sistema didático. Além disso, diversas explicações do texto aristotélico feitas pelos comentadores parecem obscuras a Batteux, que pretende esclarecer o escrito original.

Ainda no mesmo prefácio, Batteux apresenta as fontes principais em que se baseia para a defesa do princípio imitativo estabelecido pela Poética aristotélica, dando grande destaque à Arte Poética de Horácio. É interessante lembrar que Batteux realizou traduções das poéticas de Aristóteles e de Horácio. A tradução da obra de Horácio, editada em 1750, teve enorme repercussão e the valeu o convite para integrar a Acadèmie des Inscriptions (1754) e a Acadèmie Française (1761), posições que ocupou até sua morte em 1780. Dessa maneira, não é de se surpreender que Horácio seja o autor mais mencionado no Beaux arts.

Batteux diz que "a regra de Horácio se mostrou verdadeira na prova: uma pintura se assemelha a um poema". ' A seguir reitera o famoso preceito horaciano, vt pictura poesis. Ele estende esta prescrição à música e à dança, artes que constata "com espanto" também se conformarem ao princípio da imitação (1976, p. 7-8). Na Poética, Aristóteles deixa a questão inconclusa quando afirma que "a epopéia, a poesia trágica, a comédia, a ditirâmbica e, em sua maior parte [itálico meu], a aulética e a citarística [música instrumental] são imitações" (1974, 1447a15). A despeito da restrição aristotélica com relação à música, o princípio do ut pictura poesis também se estende totalmente a esta arte nas preceptivas musicais dos sécs. XVII e XVIII. No mundo luterano, são comuns afirmações como a de Johann Kuhnau (1700): “o compositor deve ser capaz de alcançar o mesmo que os mestres da oratória, escultura e da pintura." (apud Dammann, 1995, p. 117). ${ }^{2}$

Além de Horácio, Batteux, também declara seu débito para com as idéias de Nicolas Boileau (1636-1711), que editou em 1674 - em um único e mesmo volume - uma Poética em moldes horacianos e uma tradução do tratado Do Sublime, atribuído a Longino (séc. I a.C.) e redescoberto no século XVI. A tradução de Boileau constituiu o ponto de partida para inúmeras versōes subseqüentes desta obra, ao longo dos séculos XVIII e XIX. Do Sublime foi

1 "Die Regel des Horaz befand sich in der Prüfung wahr: Einem Gemälde gleicht ein Gedicht (Vt picture poësis. HOR. In: Art. Poët. v. 361)".

2 "[Der Komponist soll vorbringen] was die Meister in der Redner-Bildhauer - und Mahlerey-Kunst vermögen." 
fundamental na concepção artística do século XVIII. Segundo Longino, a principal fonte para alcançar o sublime é o entusiasmo, "eco da grandeza da alma" (1996. p. 54) 0 entusiasmo, concebido como fonte criativa natural e interna tendeu a substituir, no século XIX, a visão de arte como imitação da natureza, abrindo caminho para o romantismo. A simples menção a Boileau torna indubitável o fato que Batteux tenha tido contato com o Do Sublime, mesmo sem mencionar diretamente a obra. O conceito de entusiasmo também faz parte da teoria de Batteux acerca das artes, mas ele acomoda esse elemento (que não pertence ao pensamento poético de Aristóteles) à teoria mimética.

É possível, ainda, traçar no Beaux arts a influência do pensamento inglês, fundamentado no empirismo de John Locke (1632-1704). Batteux não cita autores britânicos diretamente, mas faz diversas referências a Baumgarten, cujo pensamento acerca do Belo provém diretamente de fontes inglesas. Com relação à conexão entre Batteux e as idéias inglesas, é interessante lembrar ainda o surgimento de uma tradução anônima do Beaux arts para o inglês, editada em Londres em 1749.

Batteux dedica um capítulo inteiro, na terceira parte de seu Beaux arts, ao estudo da música e da dança. Ele admite a música entre as artes imitativas, embora confira, como já o fizera Aristóteles, a primazia entre as artes à poesia, por ela se relacionar mais estreitamente com a razão, o mais nobre dos órgãos humanos.

No Les beaux arts réduits à un même principe é interessante observar como idéias em voga na época - discussões sobre a Beleza, o entusiasmo de Longino, questões acerca do significado da música instrumental - são mescladas à poética clássica, e utilizadas para validar a idéia de imitação e de equivalência entre as artes. Nos comentários de traduções alemãs, como a de Schlegel, essas idéias são acomodadas a idéias luteranas. 


\section{Belas Artes}

Aristóteles descreve arte como a capacidade de produzir, utilizando um método verdadeiro de raciocínio. Batteux reproduz o pensamento do estagirita, normativo até o séc. XVIII, quando afirma que as artes são "maneiras de fazer bem uma coisa" (1976, p. 14).

No sistema em uso desde a Idade Média (e ainda válido no âmbito das escolas luteranas do século XVIII), as artes se dividem entre as disciplinas mecânicas, que servem às necessidades quotidianas do homem, e liberais, cujo interesse está diretamente relacionado a interesses metafísicos e filosóficos. Esta divisão é parcialmente retomada por Batteux em seu tratado. Para o autor francês, as artes se reduzem a três espécies principais: as artes mecânicas, que visam às necessidades das pessoas, as belas artes, que se destinam apenas ao prazer (música, poesia, escultura, dança) e uma categoria mista, que "tem como objeto tanto a utilidade quanto a graça" (oratória, arquitetura) (p. 21-22). Esta divisão das artes teve ampla repercussão e se tornou dominante no século XIX.

No sistema medieval, assim como naquele proposto por Batteux, o critério de distinção entre as espécies de arte se dá pela presença ou ausência de finalidade concreta. Contudo, no pensamento medieval, as artes que não têm aplicação direta, denominadas liberais, têm interesse metafísico e filosófico, visando ao Bem Moral. Para Batteux, as artes sem utilidade concreta destinam-se unicamente ao prazer. Por isso, são consideradas belas.

A distinção entre utilidade e prazer, assim como a relação deste último com as artes (especialmente a música) tem suas raízes no pensamento da Antigüidade. Para Aristóteles, na Política, a felicidade (o prazer puro) é a finalidade última das ações humanas. O prazer é um fim em si. Para este autor, as disciplinas recomendáveis para alcançar essa felicidade última são a leitura, a escrita, o desenho, a ginástica e a música. As primeiras quatro são consideradas úteis. As disciplinas úteis são meios para alcançar o prazer: "a leitura e a escrita permitem chegar a outros conhecimentos, o desenho permite contemplar a beleza dos corpos". A música, diferentemente, coloca a alma em um estado harmônico, e por isso se relaciona diretamente tanto com o 
prazer quanto com a virtude, embora não apresente utilidade imediata. Para Aristóteles, o prazer é necessário; "buscar a utilidade emi tudo é o que menos se adapta às pessoas magnânimas e livres" (1994, 1339b25).

No século XVIII, com o aparecimento de um grande número de discussões sobre o Belo, há uma preocupação em reconhecer e definir a Beleza em si, ou seja, em fixar as qualidades intrínsecas dos objetos que geram prazer visual ou auditivo, dissociando-os de seu aspecto moral. Esta preocupação é constante em autores ingleses: o Terceiro Conde de Shaftesbury (1709) e seu discípulo Francis Hutcheson (1725) afirmam que o tipo de prazer gerado por objetos belos é distinto daquele gerado por atos moralmente bons, pois a beleza, ao contrário dos atos, não visa a nenhum fim (Hutcheson, 2003, 1,3). Para pensadores ingleses, como Hutcheson, Shaftesbury e Lord Kames, a Beleza é uma percepção. Este é um ponto significativo de ruptura no pensamento sobre as artes, pois o abandono da razão na compreensão do Belo sugere uma desvinculação entre as idéias de Beleza e Virtude, e implica na perda da função do decoro, o mecanismo que harmoniza estas duas qualidades. Estas idéias inglesas tiveram grande aceitação no mundo luterano; Kames e Shaftesbury foram traduzidos para o alemão logo após sua publicação na Inglaterra.

Para autores como Horácio, a beleza jamais se desvincula da utilidade. Esta idéia é predominante em autores musicais seiscentistas e setecentistas: Johann Mattheson, em seu Der Vollkommene Capellmeister ["O Mestre-de-Capela Perfeito"] (1739). afirma que "a principal característica da música é ser uma doutrina de educação" (1954, p. 54). ${ }^{3}$

Batteux se distancia dessas idéias ao propor a música como arte bela, vinculada apenas ao prazer. Ele não menciona diretamente nenhum dos autores ingleses envolvidos em definir as propriedades do Belo no início do século XVIII. Contudo, pressupõe influência das idéias britânicas pela via indireta da Aesthetica de Baumgarten.

\footnotetext{
3 "Das ist ein Stück der Sitten-Lehre, die ein vollenkommener Ton-Meister auf alle Weise inne haben muss, will er anders Tugenden und Laster mit seinen Klängen wohl vorstellen, und dem Gemüthe des Zuhörers die Liebe zu jenen, und den Abscheu vor diesen geschickt einflössen. Denn das ist die rechte Eigenschafft der Music, dass sie eine Zucht-Lehre vor andern sey."
} 


\section{Imitação}

Para Batteux, não apenas as artes, mas todas as obras humanas são imitações da natureza. E para ele, natureza é "tudo o que é possível ou o que podemos conceber facilmente como possível." (1976, p. 26). ${ }^{4}$ Contudo, ele afirma que na arte, a natureza não deve ser imitada servilmente: o juízo determina a escolha e objetos e de traços que a representem em sua perfeição. A imitação artística não deve se guiar pela natureza tal como a percebemos, mas excluída de seus defeitos, que ele denomina de bela natureza.

Aristóteles também pressupõe escolha na imitação. Ele diz que esta torna os homens melhores, piores ou iguais. Esta diferença separa a tragédia (que tende a imitar os homens piores) da comédia (que os imita melhores que os reais) (1974, 1448a20). Para Aristóteles, ainda, a música e a dança também podem representar essas dessemelhanças. No século XVII, este preceito aristotélico é reiterado por autores como Cesare Ripa, que afirma que a arte "imita suprindo os defeitos" (2000, p. 29). A visão de Batteux se assemelha em vários pontos à visão clássica. Contudo, a denominação bela natureza para a natureza aperfeiçoada é nova e remete diretamente às discussões setecentistas sobre a Beleza.

Para comentadores luteranos de Batteux, como Schlegel e Ruetz, natureza não se refere apenas ao que a razão ou os sentidos humanos possam conceber, mas à Onipresença Divina, que as proporções musicais imitam. Batteux não enxerga esse tipo de transcendência. Para ele, as artes "foram criadas por homens e para homens"; e visam exclusivamente seu prazer (1976, p. 22). ${ }^{5}$

Embora Batteux afirme que a razão é essencial para captar os melhores aspectos da bela natureza, ela não é o único componente na imitação. A imitação inclui ainda um componente irracional, que ele denomina entusiasmo: "as artes consistem na imitação e o objeto dessa imitação é a bela natureza, como ela se

\footnotetext{
4 "Die Natur, das heisst, alles, was ist, oder was wir uns leicht als möglich vorstellen können; diese ist das Vorbild oder das Muster der Künste."

5 "Ihre Erfinder [der Künste] sind Menschen, und für Menschen sind sie erfunden."
} 
mostra ao juízo entusiasmado." (p. 5). ${ }^{6}$ O conceito de entusiasmo, que penetrou no pensamento setecentista através de Do Sublime de Longino, é descrito por Batteux como o estado "no qual a alma, como se acesa por um fogo divino, imagina a natureza derramando vida sobre o objeto, animando-o e emprestando a ele traços moventes que nos enganam e nos captam.” (1976, p. 44). ${ }^{7}$ Este estado é fruto de uma disposição individual - o gênio - e consiste em "uma imaginação vivaz do objeto no juízo e em um movimento de alma proporcional a esse objeto." (1976. p. 48). ${ }^{8}$ Cabe então ao juízo realizar as escolhas que tornarão a imitação artística boa ou má. O entusiasmo não faz parte do pensamento aristotélico sobre a imitação. Para o estagirita, a imitação é obra exclusiva da razão.

Para Batteux, na imitação, há uma transposição de traços selecionados da natureza para diferentes objetos:

O formão do escultor representa um herói em um bloco de mármore. O pintor reproduz em uma tela, com suas cores, todos os objetos visíveis. O músico deixa desencadear-se uma tempestade através de sons artificiais. O poeta preenche a razão com imagens fingidas e o coração com emoções criadas, através da sua invenção e da consonância dos versos. (1976, p. 30). ${ }^{9}$

Johann Adolf Schlegel, comentando sua tradução do Beaux arts (1770), observa que essa asserção permite dividir a idéia de imitação em duas categorias distintas. Em primeiro lugar, aquela em que não há identidade entre os elementos naturais e sua cópia (figura humana e mármore, objetos visíveis e tela,

6 "Die Künste bestehen in der Nachahmung, und der Gegenstand dieser Nachahmung ist die schöne Natur, wie sich dieselbe dem Verstande in der Begeisterung zeigt."

7 "[Es giebt also für das Genie glückliche Augenblicke,] wo die Seele, als von einem göttlichen Feuer entflammt, sich die ganze Natur vorstellt, wo sie über die Gegenstände das Leben ausgiesst, das dieselven veseelet, und ihnen de rührenden Züge leihet, die uns täuschen, jam it Gewalt hinreizen."

8 "[Aber was ist nun denn die Begeisterung? Sie besteht nur in zwey Dingen;] nämlich in einer lebhaften Vorstellung des Gegenstandes im Verstande, und in einer Gemüthsbewegung, welche mit diesem Gegenstande in Verhältnisse steht."

9 "Auf diese Art stellt uns der Meissel des Bildhauers einen Helden in einem Marmorsteine dar. Der Maler zaubert durch seine Farben alle sichtbare Gegenstände aus der Leinewand hervor. Der Musikus lässt vermittelst künstlicher Töne ein Ungewitter toben; und der Dichter füllt durch seine Erfindung, und den Wohlklang seiner Verse, unsern Verstand mit erdichteten Bildern, und unser Herz mit gemachten Empfindungen an." 
tempestade e sons musicais); em segundo, a classe de imitações que utiliza em suas imagens os próprios elementos da natureza (a emoção é natural tanto para o homem quanto para o discurso). Com isso, Schlegel evidencia um pensamento que permeia todo o Beaux arts, embora não seja formalmente sentenciado: o de que há imitaçōes que se operam através de uma proporção (o herói está para a natureza assim como o mármore para o escultor), enquanto em outras imitações existe uma atribuição direta (as mesmas paixões são expressas pelo homem e pela arte). No segundo tipo de imitação, o elemento comum são as paixões.

Batteux retoma essa distinção na seção dedicada à música. Nesta, ele divide os discursos musicais entre aqueles que transpõem barulhos da natureza para a música (como a representação da tempestade por sons musicais) e os que expressam os "tons animados que derivam dos sentimentos". A segunda classe imitativa é considerada a mais importante. Isto ocorre porque nesta categoria, os próprios sons e movimentos que expressam as paixões reais são utilizados na música. É interessante notar que apesar desse tipo de música apresentar as próprias paixões reais, a arte deva colocá-las em cena "de maneira ordenada, enfatizada e educada", ou seja, de forma artística (1976, p. 433). ${ }^{10}$ Batteux usa muitas vezes o termo expressão para o segundo tipo de imitação, embora não o faça consistentemente nem limite este termo apenas a ele.

Batteux afirma que a música não é a única arte que expressa paixões. No capítulo dedicado à música e à dança, Batteux afirma que, na natureza, as paixões humanas são expressas de três maneiras: pelo discurso, pelos sons da voz e pelos movimentos, objetos de três artes distintas: a poesia, a música e a dança, respectivamente. Essa divisão é semelhante à estabelecida pela República (Platão, 2001, 398d) e pela Poética (Aristóteles, 1974, 1447a20), a respeito das artes que imitam com a voz. Para Platão e para Aristóteles, a imitação vocal é composta pela palavra, pela harmonia [melodia] e pelo ritmo. No Beaux arts, Batteux substitui a melodia por som da voz, ou seja, o aspecto rítmico-melódico da expressão humana. Ele também troca o conceito de ritmo por movimento. Pòrém, vale lembrar que.

10“Der Ausdruck [der Leidenschaften] wird von der Kunst [...] geordnet, verstärket, ausgebildet". 
dança e ritmo têm relação estreita, já estabelecida pelo próprio Aristóteles: ele afirma, na Poética que a dança, a arte dos movimentos, imita com o ritmo, e que "os ritmos convertidos em figuras imitam caracteres, paixões e ações" (1974, 1447a25).

Para Batteux, (e também para Platão e para Aristóteles), o discurso é a principal dentre as maneiras de imitar as paixões. Ele se relaciona com a razão, a mais nobre das faculdades humanas, e com a transmissão de conceitos, que são representações das paixões filtradas pelo juízo. O discurso é "uma linguagem introduzida, através da qual os homens podem compartilhar seus pensamentos mais claramente." (p. 392). Contudo, o uso da razão, embora confira precisão ao discurso, interrompe a comunicação direta das paixões.

Os sons da voz e os movimentos, diferentemente, representam "o dicionário da natureza simples." (Batteux, 1976, p. 392). ${ }^{11}$ Os sons e os movimentos atingem o coração diretamente, sem desvios. Se a fala é a voz da razão, que ensina e convence, o som da voz e os movimentos são a voz do coração, que move, subjuga e persuade. Esta característica oferece a estes dois modos de imitação certas vantagens sobre a fala:

O uso [dos sons da voz e dos movimentos] é mais natural, e recorremos a quando faltam as palavras. Seu uso é mais abrangente; eles são tradutores naturais que nos acompanham aos lugares mais longínquos e nos tornam inteligiveis para os povos mais primitivos e até para os animais. (Batteux, p. 391). ${ }^{12}$

Aristóteles também sustenta a precedência ontológica das paixões sobre a razão. Para ele, a alma perceptiva, onde nascem as paixões, é mais ancestral que a alma racional. Por isso, o estagirita observa que as paixões são mais eficazes para mover o ouvinte que a razão contida no discurso. Autores setecentistas se baseiam nessa idéia quando afirmam que as artes que remetem diretamente às paixões, como a música e a dança, possuem maior poder patético que o discurso. Mattheson, ao

\footnotetext{
11 “Die Geberden und Töne sind gleichsam das Wörterbuch der einfälltigen Natur.”

12 “Ihr Gebrauch [der Töne der Stimme und der Geberden] ist natürlicher, und zu ihnen nehmen wir, wenn es an Worten gebricht, unsre Zuflucht. Ihr Gebrauch ist von einem weitläufigern Umfange; sie sind ein allgemeiner Dollmetscher, der uns bis an das äusserste Ende der Welt begleitet, der uns den ungesittetsten Völkern, und den Thieren selbst, verständlich macht."
} 
discorrer sobre a "teoria natural do som", descreve propriedades éticas e medicinais da música. Essas qualidades sonoras serão lembradas por autores do final do século XVIII para valorizar a música instrumental. Contudo, para autores luteranos, as proporções sonoras não se relacionam unicamente às disposições da alma, mas também à Harmonia Divina, de onde emana o potencial movente da música. Batteux não confere este tipo de caráter metafísico à imitação musical.

Para Batteux, os três modos de expressão das paixões - discurso, sons da voz e movimentos - representam, em seu nível mais elementar, destituído de arte, a natureza pura dos pensamentos e dos sentimentos. Eles se referem a um tipo de comunicação primitiva e universal, na qual os sons da voz e os movimentos têm proeminência sobre a fala. Com o aperfeiçoamento da comunicação, as palavras foram se tornando mais importantes que os sons da voz e os movimentos, em vista de sua utilidade. Em seu mais alto grau de elaboração, estes três modos de expressão ganharam "graça, ênfase própria e natural" e a perfeição conferida pela arte, através do compasso, do movimento, da melodia e da harmonia. Daí surgiram a poesia, a música e a dança. Assim, a música e a dança constituem a perfeição máxima do som da voz e dos movimentos que acompanham a fala.

Para Batteux, o discurso se diferencia dos outros dois modos de expressão (os sons e os movimentos) pelo uso da razão. Ele permite imitar ações, e estas são o objeto da poesia. O objeto "excelente" da música e da dança, diferentemente, é a imitação dos sentimentos ou paixões:

A diferença entre a poesia, de um lado, e a música e a dança, do outro, será esta: na primeira, as paixões são utilizadas como meio e como mola propulsora, que prepara e cria as ações. Na música e na dança, entretanto, elas oferecem de certo modo o material determinado a aceitar, sustentar, conduzir e ligar as diferentes paixões que o artista quer expressar. (1976, III, 3,2, p. 394-395). ${ }^{13}$

\footnotetext{
13 "So wird der unterschied zwischen der Poesie auf der einen, und zwischen der Musik und Tanzkunst auf der andern Seite, dieser seyn; dass in der ersten die Leidenschaften, als Mittel und Triebfeder gebraucht werden, welche die Handlungen zubereiten und hervorbringen; in der Musik und Tanzkunst aber die Handlung nur gewissermaassen den Stoff giebt, der bestimmt ist, die verschiedenen Leidenschaften, die der Künstler ausdrücken will, anzunehmen, zu unterstützen, herbeyzuleiten und zu verbinden."
} 
O autor do Beaux Arts afirma que "tudo o que se dirige à razão ou ao pensamento é contrário à música. De modo inverso, tudo o que é expressão de sentimentos oferece-se por si próprio à música" (1976, p. 297). ${ }^{14}$ Para Batteux, esses modos de imitar têm um significado próprio, e podem, em certas circunstâncias, substituir a fala, quando esta falta. O canto musical pode representar tipos específicos de paixōes (amor, alegria, tristeza). Porém, ele também pode ir além destes, ao representar paixões inomináveis, que são em muito maior número e que não necessitam ser definidas, bastando que sejam sentidas:

O coração tem sua maneira própria de entender algo, que independe das palavras; quando ele é tocado, compreendeu tudo. Do mesmo modo que há coisas tão grandes que as palavras não alcançam, há também coisas finas que a palavra não pode dominar; essas se encontram principalmente nas emoções. (1976, p. 408). ${ }^{15}$

No fim do século XVIII, esta peculiaridade da música passará a representar uma grande vantagem desta arte em relação à poesia para autores alemães.

Ainda com respeito à significação dos sons da voz, Batteux afirma que, através da arte, o significado natural dos sons e dos movimentos é enfatizado 58 e, com isso, melhor compreendido. Para Batteux, "toda música e toda dança têm significado" (p. 408).

A asserção de que toda música deve necessariamente ter significado destoa da opinião de vários autores comentadores luteranos do Beaux arts: Schlegel afirma que Batteux se excede, aplicando o conceito de imitação ilimitadamente. Em sua argumentação, apresenta exemplos de música (pequenas peças musicais) e de dança (dança social) que visam apenas o prazer. Para ele, estes entretenimentos não seguem o princípio da imitação, mas o preceito luterano,

\footnotetext{
14 "Alles wass sich von den Gedächnisse oder dem Nachdenken herschreibt, ist der Musik [muss] der Musik so hartnäckig sich widersetzen. Was hingegen Ausdruck der Empfindung ist, scheint sich ihr von selbst anzubieten".

15 "Das Herz hat seine eigene Weise, etwas zu verstehen, die von den Worten nicht abhängt; und wenn es gerühret is, so hat es alles begriffen. Wie es überdem grosse Dinge giebt, die keine Worte erreichen können; eben so giebt es auch feine, deren sich die Sprache nicht bemächtigen kann; und diese finden sich vornehmlich in den Empfindungen."
} 
que prega que a música é "expressão sensorial da perfeição". Para Schlegel, embora seja indiscutível que os sons possam expressar paixões, eles também podem às vezes ser encarados simplesmente como proporções sonoras que excitam o ouvido. E as proporções consonantes são belas, por que refletem os números divinos, sem ter significado racional.

Apesar da oposição de Schlegel à idéia de que todo som deve ter significado, é ela que permite a Batteux considerar a música como uma linguagem em si, independente da palavra. A finalidade de Batteux em seu Beaux arts é demonstrar a validade das idéias de imitação e de linguagem musical. Para alcançar este propósito, apresenta argumentos que também são comumente contemplados por tratados da musica poetica germânica. Estas obras, amplamente difundidas no mundo luterano nos séculos XVI e XVII lançam mão de transposições de conceitos retóricos para estabelecer uma teoria da composição musical. Batteux, diferentemente, não procura estabelecer uma visão sistemática da composição musical; ele apenas mostra a utilidade do modelo retórico para discorrer sobre o discurso sonoro. Para isso, ele discorre brevemente sobre as virtudes da elocução musical e sobre os estágios pressupostos no processo de composição.

Batteux não devota muita atenção à música instrumental no Beaux Arts. No capítulo dedicado à música e à dança, menciona-a de passagem, dizendo que a sinfonia, devido à ausência das palavras, tem apenas "meio ser", ou seja, constitui uma arte de menor importância em relação à música cantada. No entanto, para Batteux, a ausência das palavras compromete a comunicação de conceitos, mas não impede a expressão das paixões, já que os sons têm um significado primitivo e universal. Para ele, uma sucessão de emoções cria um discurso que imita um sentimento, da mesma maneira que os pensamentos geram um discurso verbal que imita uma ação. Este sentimento pode ser racionalmente compreendido, como as paixões teorizadas por obras como as éticas aristotélicas (amor, ira etc.), ou constituir um tipo de emoção que escapa ao poder lógico da palavra. Vimos ainda que Batteux considera o segundo tipo como o mais freqüente na música. Possivelmente é essa constatação que leva Batteux a modalizar sua asserção: "a 
sucessão de movimentos de ânimo constrói de certa maneira um discurso" (1976. p. 406). Apesar dessa limitante, as mesmas regras que ditam o discurso verbal valem também para o discurso musical: as emoções devem ser encadeadas de maneira ordenada e discursiva. Para Batteux, a diferença principal entre o discurso verbal e o musical reside no fato que "o discurso julga com a razão e a música, com a emoção". A música é uma língua natural que discursa com sons, e a maior qualidade do discurso musical, assim como do verbal, é a eloqüência.

Johann Mattheson, em seu Vollkommene Capellmeister ["O Mestre de Capela Perfeito"], (1739), também reitera a idéia de que os sons constituam um discurso eloqüente. O livro de Mattheson, como o de Batteux, foi amplamente lido no século XVIII. A obra de Mattheson estava presente nas bibliotecas de ao menos dois importantes compositores no fim do século: Joseph Haydn (1732-1809) e Ludwig van Beethoven (1770-1827). Nela, ele diz que

é preciso saber que também sem palavras, na música puramente instrumental, sempre e em cada melodia, o propósito deve ser a representação da afecção dominante, de modo que os instrumentos. através do som, constituam um discurso claro e eloqüente. (Mattheson. 1954, p. 127). ${ }^{16}$

Batteux compara a música com a gramática e com a dialética do discurso verbal. A música, como o discurso, deve apresentar uma boa conexão lógica entre seus elementos: "quando [os sons] não significam nada, são como aqueles movimentos do orador que são apenas sinais que indicam que ele está vivo. ou como aqueles versos que não são nada além de ornamentos vazios." (1976, p. 405). ${ }^{17}$

\footnotetext{
16 "Allein, man muss doch hiebey wissen, dass auch ohne Worte, in der blossen Instrumental-Music allemahl und bey einer ieden Melodie, die Absicht auf eine Vorstellung der regierenden Gemüths-Neigung gerichtet seyn müsse, so dass die Instrumente, mittelst des Klanges, gleichsam einen reddenden und verständlichen Vortrag machen."

17 "Wenn sie [die Töne des mathematischen Accordes] nichts bedeuten, so werde ich sie mit denen Geberden der Redner vergleichen, die weiter nichts, als blosse Zeichen sind, dass der Redner noch am Leben ist; oder mit denen künstlichen Versen, die nichts, als ein leerer Zierrath, sind."
} 
O autor do Beaux arts diz que, na natureza, não há regra para que as emoções emprestem aparência aos tons e gestos. Contudo, na arte, há preceitos fixos, limites que não devem ser ultrapassados. Com isso, ele estabelece as virtudes da elocução musical, que consistem em cinco pontos principais: clareza, correção, adequação, não-artificialidade e novidade.

Em primeiro lugar, todo discurso deve ter clareza. Esta é também a principal virtude da expressão nos manuais retóricos de Aristóteles, Cícero e Quintiliano. Batteux cita este último diretamente: prima est eloquentiae virtus perspicuitas (a primeira virtude da elocução é a clareza). Para Batteux, para que o discurso verbal šeja claro, cada som "deve contribuir para o entendimento do todo, mesmo que seja apenas uma expressão correspondente a uma palavra ou a uma sílaba." Na música, igualmente, "cada som, cada melodia, cada período deve dirigir-se para um sentimento ou provocar um sentimento." (p. 411). ${ }^{18}$

A idéia de que os sons são análogos às palavras no discurso musical é recorrente em autores do século XVII e XVIII. Matthesson, em seu Volkommene Capellmeister, também nos diz que "os sons são as palavras da música". Forkel, em 1784, transforma essa premissa na base de sua gramática musical. Rolf Dammann mostra que a virtude retórica da clareza também era entendida como a principal qualidade do discurso musical para autores da musica poetica luterana. Para esses autores, a idéia de clareza reflete-se no fato de que a música deve ser racionalmente compreensível e capaz de ser conhecida pela inteligência (Dammann, 1995, p. 117). Batteux, harmonizando idéias estéticas e retóricas a respeito dessa questão, afirma que a clareza pode também ser objeto de percepção sensorial (sentimento). Essa posição é inaceitável para os autores da musica poética, para quem a clareza é uma qualidade racional.

A segunda virtude da elocução, para Batteux, é a correção. Ela se mistura com a terceira virtude, segundo a qual os sentimentos devem ser expressos adequadamente: "os sentimentos são como as cores. Se as representarmos mais fracas ou mais fortes do que se deve, privando-as de seu grau adequado,

18 "Jeder Ton, jede Modulation, jeder Absatz muss uns entweder auf eine Empfindung leiten, oder eine Empfindung in uns erregen." 
modificaremos sua natureza ou as tornaremos ambíguas." (p. 411-412). ${ }^{19}$ Para Batteux, ainda, é preciso ter em mente que, na arte, as paixões devem ser representadas mais intensas do que na natureza, para que não sejam entendidas como imitações servis. Contudo, a quarta virtude da elocução prescreve que o artista também deve evitar o vício contrário, o do exagero, que gera a afetação.

A adequação ou decoro também é prescrição clássica do discurso verbal, e faz parte da musica poetica luterana, desde os escritos de Burmeister (1606). Para Mattheson, no Vollkommene Capellmeister, o decoro é o mais importante princípio geral da música, e inaugura seu livro do seguinte modo:

Todas as coisas devem cantar convenientemente. Sob a palavrinha conveniente [gehörig], da qual advém a maior força deste princípio geral, entendemos, como é fácil de se avaliar, todas as circunstâncias agradáveis e verdadeiras propriedades do cantar e tocar, tanto com respeito ao movimento dos afetos, quanto [com respeito] aos' estilos de escrita, palavras, melodia, harmonia, etc. Do princípio acima fluem necessariamente, como de uma fonte clara, todos os assuntos seguintes [que Mattheson tratará ao longo do livro]. (1954, p. 2). ${ }^{20}$

Mattheson alerta para o vício da afetação. Para ele, "quando os estilos não condizem com as pessoas, com as coisas, com os pensamentos e com a intenção da música, nenhum deles é natural. O estilo empolado é o menos natural de todos." (1954, p. 71). ${ }^{21}$ Batteux também reitera a adequação entre o estilo da representação e a matéria representada: "o que esperaríamos de

\footnotetext{
19 "Es verhält sich mit den Empfindungen, wie mit den Farben. Wenn man sie stärker oder schwächer aufträgt als man soll, so entzieht man ihnen ihren gehörigen Grad, oder man verändert ihre Natur, oder man macht sie zweydeutig."
}

20 “Alles muss gehörig singen. Unter dem Wörtlein gehörig, also worauf die meiste Stärcke diesess allgemeinen Grund-Satzes ankömmt, begreiffen wir hieselbst, wie leicht zu ermessen, alle angenehme Umstände und wahre Eigenschafften des Singens und Spielens, sowol in Ansehung der Gemüths-Bewegungen, als Schreib-Arten, Worte, Melodie, Harmonie, u.s.w."

21 "Wenn also die Schreib-Arten mit den vorzustellenden Personen, Dingen, Gedancken und Verrichtungen nicht übereinkommen so ist deren keine einzige natütlich; die schwülstige am allerwenigsten." 
uma oração cuja primeira parte fosse adequada a um magistrado e a segunda, a um lacaio na comédia?" (1976, p. 411). ${ }^{22}$

A última virtude do estilo, para Batteux, é a novidade das expressões. Para ele, a monotonia gera inatividade e indiferença em todas as artes, principalmente na música. Por isso, é necessário variar tonalidades, movimentos e paixões. A oratória clássica e seiscentista também recomenda a novidade no estilo. O jesuíta Emanuele Tesauro, em seu "Cannocchiale Aristotelico" ["A Luneta Aristotélica"], (1650), quando trata da elocução, reproduz a Retórica de Aristóteles, e preconiza que as figuras da oração apresentem "ensinamento conjunto com a novidade, para que o ouvinte ao mesmo tempo aprenda gozando e goze aprendendo.", (2000, p. 124).

As idéias de Batteux a respeito das virtudes da elocução demonstram claro vínculo com as retóricas clássicas e com tratados da musica poetica luterana, especialmente a obra de Mattheson, que trata extensamente sobre as qualidades do discurso musical. Após tratar destas virtudes, Batteux trata sucintamente dos estágios da composição musical. Seguindo a tradição já prescrita pelos manuais de retórica e pelos tratados da musica poetica, ele dedica a parte mais longa da criação musical à invenção, parte relacionada à confecção do tema sonoro. Para Batteux, o tema deve refletir o caráter principal da expressão sentimental. É ele que determinará se o estilo da oração será elevado ou simples, delicado ou enfático. Esta prescrição já está contida nos tratados seiscentistas da musica poetica. Ainda com relação à invenção, Batteux diz que "os lugares [comuns] que o bom compositor aprova são aqueles em que a compreensão da música é clara, sem obscuridade nem ambigüidade". Por isso, ele diz que o compositor deve escolher preferencialmente as paixões mais fáceis de expressar e mais compreensíveis para o ouvinte, como aquelas descritas nas éticas e na Retórica aristotélica. Em tratados musicais do séc. XVIII, estas paixões também são descritas de maneira mecânica, de acordo com a concepção cartesiana.

\footnotetext{
22 "Was würde man aber wohl von einer Rede sagen, deren erster Theil sich in den Mund einer Magistratsperson, der andre aber in den Mund eines Lakays in der Komödie gut schicken würde?"
} 
Autores setecentistas de poéticas musicais, como Heinichen, sugerem que o compositor recorra a lugares-comuns para encontrar os temas adequados a seus discursos musicais. Segundo Dammann, o uso de lugarescomuns constitui a ligação mais sólida entre música e linguagem no século XVIII (1995, p. 117).

A invenção pressupõe também a agudeza como mediadora entre os lugares-comuns genéricos e suas aplicações particulares, que constituem os temas. Johann Christoph Gottsched, um dos tradutores de Batteux, escreve que

todos os inventores devem ter mentes agudas e engenhosas: de outro modo, eles apenas imitariam os artifícios de outros autores em casos semelhantes. É preciso engenho para perceber em parte a semelhança entre os casos e a imitação, e em parte a semelhança entre o exemplo e a imitação, como os pintores, escultores, arquitetos, poetas, oradores, músicos e comediantes nos mostram. Ingenio hic maxime opus est. (1973, p. 490). ${ }^{23}$

A opinião de Gottsched se aproxima bastante da de Batteux, que também afirma que a imitação deve evidenciar a perspicácia e a agudeza do compositor.

Após descrever a invenção, Batteux passa à próxima etapa de produção do discurso, a disposição. Ele não se preocupa em descrever detalhadamente a estrutura do discurso 'musical - esse propósito foge ao âmbito de seu tratado. Para ele, basta reiterar a necessidade de uma ordem que satisfaça os aspectos estéticos da unidade e da variedade. A unidade se daria na reunião de melodias ou danças que conformam a disposição geral da obra. A variedade resultaria da justaposição e da hierarquia das diferentes paixões representadas em uma peça.

Mattheson, quando explica a disposição musical, compara a ordem da composição com a ordem de um projeto arquitetônico:

23 "Es müssen also alle Erfinder witzige, und folglich auch scharfsinnige Köpfe haben: es wäre denn, dass sie nur anderer Leute Kunstgriffe in ähnlichen Fällen nachahmen wollten. Doch gehöret auch hierzu Witz, indem man theils die Aehnlichkeit der Fälle; theils auch die Aehnlichkeit des Musters mit seiner Nachahmung einsehen muss: wie die Exempel der Maler, Bildhauer, Baumeister, Poeten, Redner, Tonkünstler und Komödianten soches erweisen. Ingenio hic maxime opus est." 
No que em primeiro lugar concerne à disposição, a organização fluente das partes e circunstâncias da melodia ou em toda a obra musical é quase como a maneira que dispomos e projetamos um edifício; fazemos um projeto ou rascunho para mostrar onde serão colocadas uma sala, um quarto, uma câmara, etc." (1954, p. 235). ${ }^{24}$

Para Batteux, como para Mattheson, ó discurso deve ser claramente ordenado. No entanto, para Mattheson, o critério principal é a utilidade, ou seja, a eficácia persuasiva, enquanto para Batteux, as normas estéticas de unidade e de variedade determinarão a beleza do discurso.

Batteux finaliza sua discussão sobre a música tratando da elocução sonora. Ele diz que o compositor "imita o orador e utiliza todas as figuras e variedades que a arte the apresenta sem alterar o tom principal de seu estilo [Schreibart]" (p. 411). A proposição de Batteux quanto ao uso das figuras para a elocução musical está totalmente de acordo com a tradição de diversos tratados seiscentisas e setecentistas que propuseram extensas catalogações e descrições de figuras musicais. a transposição de denominações derivadas da retórica para procedimentos musicais específicos constituem a ligação mais antiga entre música e retórica. No primeiro tratado a apresentar figuras musicais, o autor Joachim Burmeister (1606) afirma estar ciente da novidade de seu vocabulário musical.

Encerrando este artigo, é possível constatar que idéias contidas no Beaux arts a respeito da Beleza como resultante do prazer sensorial e com respeito ao papel do entusiasmo no julgamento do Belo se associam, no mundo luterano, com a idéia de que o prazer musical resulta diretamente da percepção intuitiva das proporções divinas. Contudo, a transcendência proposta pelo entusiasmo em Batteux não tem conotações teológicas, como na concepção luterana.

24 "Was zum ersten die Disposition betrifft, so ist eine nette Anordnung aller Theile und Umstände in der Melodie, oder in einem gantzen melodischen Wercke, fast auf die Art, wie man ein Gebäude einrichtet und abzeichnet, einen Entwurff oder Riss machete, um anzuzeigen, wo ein Saal, eine Stube, eine Kammer u.s.w. angeleget werden sollen." 
Para Batteux, 'todas as artes, entre elas a música, constituem imitações da natureza. Para ele, natureza é tudo o que se pode conceber como possível. Autores luteranos também afirmam que a música imita a natureza, mas concebem esta última como a Onipresença Divina, que transcende a razão humana. Com isso, garantem a validade geral do princípio de imitação sem descartar o aspecto transcendente.

Schlegel, em seu comentário a Batteux, diz que algumas imitações expressam a natureza diretamente, enquanto que outras o fazem por meio de representação. A música se inclui na primeira categoria, já que seu objeto são as próprias paixões humanas. Isto confere certa superioridade a esta arte. No pensamento luterano, a música também tem posição elevada, sendo superada unicamente pela Palavra Divina. Este ponto em comum é muito explorado pelos comentadores alemães de Batteux, como Ruetz e Schlegel.

Batteux afirma que toda arte, entre elas a música, deve ter um sentido inteligível. Com isso, ele propõe que a música constitui um discurso lógico, embora fundamentado na percepção sensorial da paixão. Para ele, a música é uma língua natural que discursa com sons, e a maior qualidade do discurso musical, assim como do verbal, é a eloqüência. Esta concepção retórica corresponde exatamente àquela proposta pelas poéticas musicais luteranas.

As similaridades naturalmente existentes entre o pensamento de Batteux e a concepção musical luterana podem explicar o porquê do sucesso de Batteux no mundo germânico, e as sínteses resultantes da aproximação da concepção clássica das artes como imitação e as poéticas musicais alemãs estão na base da compreensão musical romântica, que se consolida na Alemanha no início do séc. XIX.

\section{Referências}

ARISTÓTELES. Política. Madrid: Gredos, 1994

. Poética. Madrid: Gredos, 1974.

BATTEUX. Einschränkung der schönen Künste auf einen einigen Grundsatz Hildesheim: Olms, 1976 [Leipzig, 1770]. Versão alemã de Les beaux arts réduits a un même principe. Paris, 1746. 
DAMMANN, Rolf. Der Musikbegriff im deutschen Barock. Laaber: Laaber Verlag, 1995.

GOTTSCHED, Johann Christoph. Ausführliche Redekunst. Hildesheim: Olms, 1973 [Leipzig, 1762]. HUTCHESON, Francis. An Inquiry into the Original of our Ideas of Beauty and Virtue. In: Two Treatises in which the Principles of the late Earl of Shaftesbury are explain'd and defended. London: Elibron, 2003 [London, 1725].

KLEIN, Robert. Giudizio e Gusto na Teoria da Arte do Cinquecento. In: A Forma e o Inteligível. São Paulo: Edusp, 1998.

LONGINO. Do Sublime. São Paulo: Martins. Fontes, 1996, IX, 2, p. 54.

MATTHESON, Johann. Der Vollkommene Capellmeister. Kassel: Bärenreiter, 1954 [Hamburg, 1739].

PLATÃO. República. Lisboa: Calouste Gulbenkian, 2001.

RIPA, Cesare. Iconologia Milano: Neri Pozza, 2000 [1618]. 1. ed.1593.

TESAURO, Emanuele. // Cannocchiale Aristotelico Savigliano: Editrice Artistica Piemontese, 2000 [Torino, 1670]. 1. ed. 1652.

Mônica Lucas: monicalucas@usp.br

Artigo recebido e aprovado em 30 de abril de 2009 